Çukurova Üniversitesi Mühendislik Mimarlık Fakültesi Dergisi, 33(2), ss. 153-164, Haziran 2018

Çukurova University Journal of the Faculty of Engineering and Architecture, 33(2), pp. 153-164, June 2018

\title{
Uçucu Kül Yerine Kullanılan Atık Cam Tozunun Kendiliğinden Yerleşen Betonların Taze, Mekanik ve Durabilite Özellikleri Üzerine Etkisi
}

\author{
Hasan Erhan YÜCEL ${ }^{* 1}$ \\ ${ }^{l}$ Niğde Ömer Halisdemir Üniversitesi, Mühendislik Fakültesi, İnşaat Mühendisliği Bölümü, \\ Niğde
}

Geliş tarihi: 01.03.2018～Kabul tarihi: 29.06.2018

$\ddot{\mathbf{O} z}$

Bu çalışmada, uçucu kül (UK) yerine atık cam tozu (ACT) kullanılarak kendiliğinden yerleşen beton (KYB) üretilmiş ve ACT'nin KYB üzerindeki etkileri araştırılmıştır. KYB'ler, $550 \mathrm{~kg} / \mathrm{m}^{3}$ bağlayıcı içeriğinin yanı sıra $0,32 \mathrm{su} /$ bağlayıcı oranıyla ve $700 \pm 10 \mathrm{~mm}$ sabit bir yayılma çapıyla üretilmiştir. Öncelikle, ACT kullanılmaksızın çimento ve UK ile kontrol karışımı üretilmiş, sonrasında UK yerine ACT $\% 5, \% 10, \% 15$ ve $\% 20$ oranlarında kullanılarak diğer 4 karışım tasarlanmıștır. KYB'lerin taze özelliklerini belirlemek amacıyla yayılma tablasında yayılma çapı ve $\mathrm{T}_{500(\mathrm{~mm})}$ slump yayılma süresi, $\mathrm{V}$ hunisinde boşalma süresi ve L kutusunda yükseklik oranı deneyleri yapılmıştır. Sertleşmiş halde ise KYB'lerin mekanik özelliklerini tespit etmek için basınç, yarmada çekme ve eğilme deneyleri, durabilite özelliklerini belirlemek amacıyla kılcal su geçirimliliği ve hızlı klor geçirimliliği deneyleri yapılmıştır. Sonuçlara göre ACT, KYB'lerin yayılma çapı ve L kutusu yükseklik oranı değerlerini azaltırken, $T_{500(\mathrm{~mm})}$ slump yayılma süresi ve V hunisi boşalma süresi değerlerini artırmıştır. Ayrıca, UK yerine kullanılan ACT miktarı arttıkça KYB'nin mekanik ve durabilite özellikleri iyileşmiştir.

Anahtar Kelimeler: Kendiliğinden yerleşen beton, Atık cam tozu, Uçucu kül, Taze özellikler, Mekanik özellikler, Durabilite özellikleri

\section{The Effect of Waste Glass Powder using Instead of Fly Ash on the Fresh, Mechanical and Durability Properties of Self Compacting Concretes}

\begin{abstract}
In this study, self-compacting concrete (SCC) was produced by using waste glass powder (WGP) instead of fly ash (FA) and the effects of WGP on SCC were investigated. SCCs were produced with 0.32 water/binder ratio and a constant slump diameter of $700 \pm 10 \mathrm{~mm}$ as well as $550 \mathrm{~kg} / \mathrm{m}^{3}$ binder content. Firstly, the control mixture with cement and FA was produced without WGP, then, other four mixtures were designed using WGP in the ratios of 5\%,10\%, 15\% and 20\% instead of FA. Slump diameter and $\mathrm{T}_{500(\mathrm{~mm})}$ slump flow time in slump table, discharge time in V-funnel and height ratio in L-box tests were performed in order to determine the fresh properties of the SCCs. In the hardened state, compressive, splitting tensile and flexural tests in order to indentify the mechanical properties of SCCs, water sorptivity
\end{abstract}

*Sorumlu yazar (Corresponding author): Hasan Erhan YÜCEL, heyucel@ohu.edu.tr 
and rapid chloride permeability tests in order to determine durability properties were performed. According to the results, while WGP decreased values of slump diameter and L-box height ratio of SCCs, values of $\mathrm{T}_{500(\mathrm{~mm})}$ slump flow time and $\mathrm{V}$-funnel discharge time were increased. In addition, as the amount of WGP used in place of the UK increased, the mechanical and durability properties of SCC improved.

Keywords: Self-compacting concrete, Waste glass powder, Fly ash, Fresh properties, Mechanical properties, Durability properties

\section{GíRiș}

Artan yaşam standartları ve gelişen teknoloji ile birlikte, betonun istenilen dayanım ve dayanıklılık gibi performans özelliklerini sağlaması ve taze halde iken yapı elemanlarının özellikle sık donatılı bölgelerinde kendi ağırlığı altında kolay bir şekilde yerleşebilmesi istenmektedir. Yüksek akışkanlık özelliği ile karakterize edilen kendiliğinden yerleşen beton (KYB), istenilen bu tür farklı durumları sağlayabilen özel bir beton türüdür. KYB'ye yüksek akışkanlık özelliğini kazandıran yüksek oranda su azaltıcı kimyasal katkı (süper akışkanlaştırıcı-SA), işlenebilirliği artırmasının yanı sıra ayrışmayı ve terlemeyi azaltır [1]. Bunlara ek olarak, KYB, inşaat sırasındaki mekanik sıkıştırmayı gidermesinden dolayı çalışma güvenliğini artırmakla birlikte atık malzeme içeriği ile çevresel problemleri de önemli derecede azaltmaktadır [2,3].

KYB'nin su/bağlayıcı oranı ve iri agrega içeriği geleneksel betona oranla daha düşüktür. KYB silis dumanı, uçucu kül, yüksek firın cürufu, pomza tozu ve pirinç kabuğu külü gibi ince taneciklerin büyük miktarlarını içerir [4]. Bu tür ince malzemelerin artmasıyla birlikte, KYB dayanım ve dayanıklılık açısından yüksek performans gösterir [1]. Puzolanik özellik gösteren ve endüstriyel birer atık olan bu minerallerin beton üretiminde çimento yerine kullanılmasının bir diğer önemli nedeni ise çimento üretimi esnasında ortaya çıkan $\mathrm{CO}_{2}$ yayılımının yüksek olmasıdır. $\mathrm{CO}_{2}$, çimento üretim esnasında kireçtaşının $\left(\mathrm{CaCO}_{3}\right)$ kalsinasyonu ve fosil yakıtların yakılması sonucu ortaya çıkmaktadır. $\mathrm{CO}_{2}$ yayılımının \%60'1 ham madde olarak kullanılan kireçtaşının kalsinasyonundan gelirken, \%40'1 ise kireçtaşı kalsinasyonu ve klinker üretimi için gerekli sıcaklığı sağlamak amacıyla fosil yakıtların yakılması sonucu ortaya çıkmaktadır [5]. Çimento üretiminde yüksek oranda doğal kaynak tüketimi ve $\mathrm{CO}_{2}$ yayılımı olduğu literatür çalışmalarıyla da bilinen bir gerçektir [6,7]. Beton içerisinde, özellikle KYB gibi çimento içeriğinin fazla olduğu beton türlerinde yüksek oranda çimento kullanıldığ1 bilinmektedir. $\mathrm{Bu}$ nedenle, çimento yerine kullanılabilecek endüstriyel yan ürünlerin önemi son derece büyüktür. Bu çalışmada çimento yerine kullanılan, uçucu kül (UK) ve atık cam tozu (ACT) endüstriyel birer atık malzemedir.

Kömürün yakılması sonucunda elde edilen ve endüstriyel bir atık olan UK, KYB üretiminde oldukça yaygın bir şekilde kullanılmaktadır. Bilindiği gibi, bu mineralin ince taneli ve puzolanik kökenli bir malzeme olması KYB'deki performansı olumlu yönde etkilemektedir [8-10]. Literatür çalışmalarına göre, KYB'de kullanılacak olan çimento miktarının en fazla \%30'una kadar UK'nin kullanılması, KYB'de işlenebilirlik ve basınç dayanımları açısından olumlu sonuçlar elde edilmesini sağlamaktadır [11-13].

Geri dönüşümden alınan temiz pencere camlarının öğütülmesiyle oluşan ACT, amorf bir yapıya ve yüksek derecede silis $\left(\mathrm{SiO}_{2}>\% 70\right)$ içeriğine sahiptir [14]. ACT'nin çimentoyla birlikte hidratasyona girebildiği doğrulandıktan sonra betonda kullanımının uygun olduğu belirlenmiştir $[15,16]$. Bu mineralin tanecik boyutu 0,075 mm'den daha az olduğu zaman puzolanik özellik gösterir ve alternatif bir çimento tamamlayıcı malzeme olarak beton içerisinde kullanılabilir [14]. Endüstriyel bir atık olan ACT, KYB içerisinde daha önceki çalışmalarda denenmiş, ancak sadece mekanik özelliklere olan etkisi belirlenmiştir. Bununla birlikte, ACT'nin geleneksel beton üzerindeki etkilerinin araştırıldığ çalışmalara göre dayanım ve dayanıklılığı 
geliştirdiği bilinmektedir [15,17-19]. Tüm bu etkenler göz önüne alındığında, ACT'nin KYB içerisinde kullanılarak, KYB'nin taze, mekanik ve durabilite özelliklerine olan etkilerinin belirlenmesi oldukça önemlidir. Ayrıca, KYB'lerde ACT'nin UK yerine kullanımı ve karşılaştırılması ile alakalı bir çalışmaya rastlanmamıştır.

Bu çalışmada, geleneksel beton, harç ve KYB gibi çimento esaslı karışımlarda uygun oranlarda kullanıldığında işlenebilirlik, mekanik ve durabilite özelliklerini iyileştiren UK ile geleneksel betonda kullanılan ancak KYB'de yeni denenen ACT kullanımının KYB karışımları üzerindeki etkilerinin belirlenmesi amaçlanmıştır. $\mathrm{Bu}$ amaç doğrultusunda toplam 5 farklı karışım üretilmiştir. İlk olarak toplam bağlayıcı içeriğinin \%20'si oranında UK kullanılarak kontrol karışımı tasarlanmıştır. Daha sonra ACT'nin, KYB üzerindeki etkilerini belirlemek ve UK ile farklılıklarını tespit edebilmek için çimento toplam bağlayıcı içeriğinin \%80'i olarak sabit tutulup, UK yerine $\% 5, \% 10, \% 15$ ve $\% 20$ oranlarında ACT eklenerek diğer 4 karışımın tasarımı yapılmıştır. Üretilen KYB'lere taze halde iken, yayılma tablasında yayılma çapı ve $\mathrm{T}_{500(\mathrm{~mm})}$ slump yayılma süresi, V hunisinde boşalma süresi ve L kutusunda yükseklik oranı deneyleri yapılmıştır. KYB'lerin 28. ve 56. gündeki mekanik ve durabilite özelliklerini tespit etmek amacıyla, basınç, eğilme, yarmada çekme, kılcal su geçirimliliği ve hızlı klor geçirimliliği deneyleri uygulanmıştır.

\section{MATERYAL VE METOT}

\subsection{Malzemeler}

Bu çalışmada temel bağlayıcı olarak, CEM I 42.5 $\mathrm{R}$ tipi portland çimentosu kullanılmıştır. İkinci bağlayıcı mineral olarak ise toplam bağlayıcı içeriğinin \%20'si yerine, belirli oranlarda F sınıfı UK ve öğütülmüş ACT kullanılmıştır. Çimento, UK ve ACT'nin fiziksel ve kimyasal özellikleri Çizelge 1'de sunulmuştur. Ayrıca, bu malzemelerin tane boyutu dağılımları Şekil 1'de gösterilmektedir. UK ve ACT minerallerinin SEM görüntüleri ise Şekil 2'de verilmiştir. KYB'de istenilen işlenebilirliği elde edebilmek için yoğunluğu 1,07 olan ve aktif içerik olarak polikarboksilat eter bulunduran süper akışkanlaştırıcı (SA) kimyasal katkı maddesi olarak kullanılmıştır.

Çizelge 1. Çimento, UK ve ACT'nin fiziksel ve kimyasal özellikleri

\begin{tabular}{|c|c|c|c|}
\hline $\begin{array}{c}\text { Kimyasal } \\
\text { Analizleri (\%) }\end{array}$ & Çimento & UK & ACT \\
\hline $\mathrm{CaO}$ & 62,58 & 2,24 & 9,89 \\
\hline $\mathrm{SiO}_{2}$ & 20,25 & 57,20 & 73,90 \\
\hline $\mathrm{Al}_{2} \mathrm{O}_{3}$ & 5,31 & 24,40 & 1,69 \\
\hline $\mathrm{Fe}_{2} \mathrm{O}_{3}$ & 4,04 & 7,10 & 0,98 \\
\hline $\mathrm{MgO}$ & 2,82 & 2,40 & 2,69 \\
\hline $\mathrm{SO}_{3}$ & 2,73 & 0,29 & 1,72 \\
\hline $\mathrm{K}_{2} \mathrm{O}$ & 0,92 & 3,37 & 0,20 \\
\hline $\mathrm{Na}_{2} \mathrm{O}$ & 0,22 & 0,38 & 7,86 \\
\hline $\mathrm{K}_{12 d ı r m a ~ K a y b 1}$ & 2,99 & 1,52 & - \\
\hline Özgül Ağırlık & 3,15 & 2,04 & 2,60 \\
\hline $\begin{array}{c}\text { Özgül Yüzey Alan1 } \\
\left(m^{2} / \mathrm{kg}\right)\end{array}$ & 326 & 379 & 492 \\
\hline
\end{tabular}

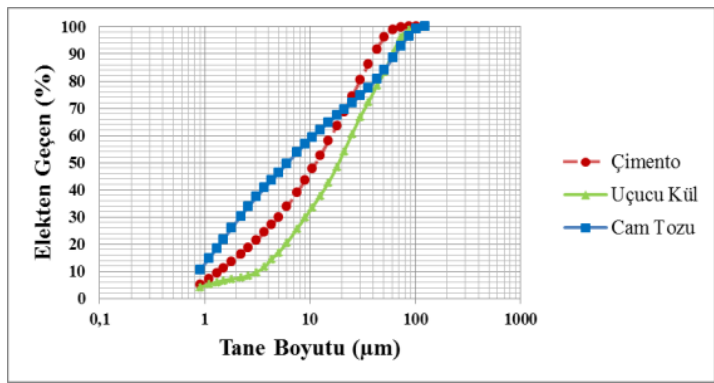

Şekil 1. KYB karışımında kullanılan çimento, UK ve ACT'nin tane boyutu dağılımları

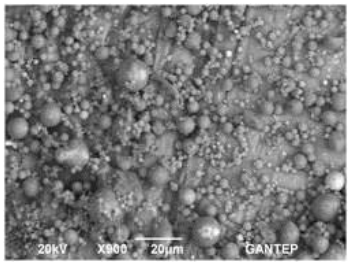

(a)

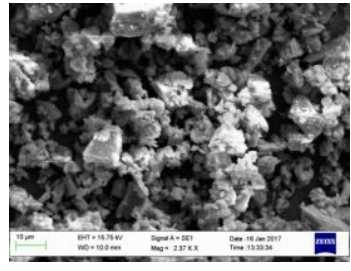

(b)
Şekil 2. a) UK'nin SEM görüntüsü, b) ACT'nin SEM görüntüsü

KYB karışımlarında kullanılan agregalar dere malzemesi olup konkasör sahasında istenilen boyutlara getirilmiştir. KYB üretimi için $\% 50$ oranında ince agrega (doğal kum+kırma kum) ve 
Uçucu Kül Yerine Kullanılan Atık Cam Tozunun Kendiliğinden Yerleşen Betonların Taze, Mekanik ve Durabilite Özellikleri Üzerine Etkisi

$\% 50$ oranında iri agrega kullanılmıştır. Kullanılan bu agregaların elek analizi ve fiziksel özellikleri Çizelge 2'de verilirken, tane boyutu dağılımları, Şekil 3'de grafiksel olarak gösterilmektedir.

Çizelge 2. Agregaların elek analizi ve fiziksel özellikleri

\begin{tabular}{|c|c|c|c|}
\hline \multirow{2}{*}{ Elek Çapı (mm) } & \multicolumn{3}{|c|}{ Doğal Agrega } \\
& $\%$ Elekten Geçen) \\
\cline { 2 - 4 } & $\begin{array}{c}\text { Doğal } \\
\text { Kum }\end{array}$ & $\begin{array}{c}\text { Kırma } \\
\text { Kum }\end{array}$ & $\begin{array}{c}\text { İri } \\
\text { Agrega }\end{array}$ \\
\hline 16 & 100 & 100 & 100 \\
\hline 8 & 99,7 & 100 & 31,5 \\
\hline 4 & 94,5 & 99,2 & 0,4 \\
\hline 2 & 58,7 & 62,9 & 0 \\
\hline 1 & 38,2 & 43,7 & 0 \\
\hline 0,5 & 24,9 & 33,9 & 0 \\
\hline 0,25 & 5,4 & 22,6 & 0 \\
\hline İncelik Modülü & 2,79 & 2,38 & 5,68 \\
\hline Özgül Ağırlık & 2,67 & 2,63 & 2,65 \\
\hline
\end{tabular}

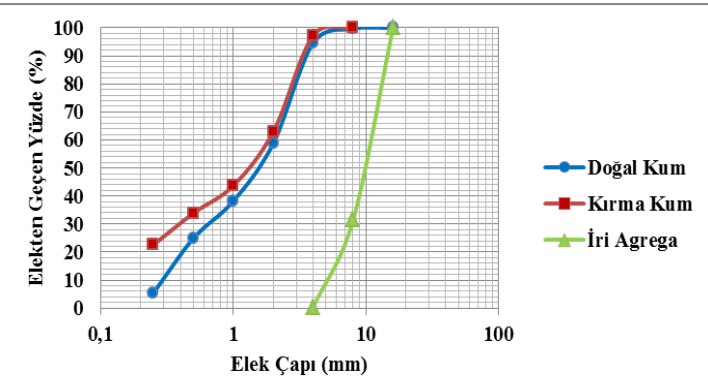

Şekil 3. KYB karışımında kullanılan agregaların tane boyutu dağılımları

\subsection{Beton Karıșım Oranları ve Üretimi}

KYB'nin, karıștırma ve döküm prosedürleri, ASTM C192/C192M [20] standardına uygun olarak yapılmış olup, tüm karışımlar bu prosedüre göre üretilmiştir. Bu çalışmada, su/bağlayıcı oranı 0,32 oranında sabit tutularak, $700 \pm 10 \mathrm{~mm}$ sabit bir yayılma çapıyla, 5 farklı KYB karışımı hazırlanmıştır. Toplam bağlayıcı miktarı 550 $\mathrm{kg} / \mathrm{m}^{3}$ olarak belirlenmiş olup, tasarlanan tüm karışımlarda çimento içeriği, toplam bağlayıcı miktarının \%80'ini oluşturmaktadır. Kontrol karışımı toplam bağlayıcı miktarının \%20'si oranında UK kullanılarak üretilmiş olup, diğer 4 karışım UK yerine $\% 5, \% 10, \% 15$ ve $\% 20$ oranlarında ACT kullanılarak hazırlanmıştır. Bu çalışmada kullanılan bütün karışımların malzeme miktarları Çizelge 3'de verilmiştir. Çizelge 3'den de görüldüğü üzere istenilen işlenebilirliği sağlamak amacıyla karışımlarda kullanılan SA oranları farklıdır. Kontrol karışımı ikinci bir bağlayıcı olarak sadece UK içerdiği için KYBK olarak adlandırılmıştır. Ayrıca Çizelge 3'de verilen kod numaraları şu şekilde açıklanabilir. KYBC5 kod numarasındaki KYB, kendiliğinden yerleşen betonu ifade ederken, C, ACT'yi, 5 ise karışımın toplam bağlayıcı miktarının \%5'i oranında ACT içerdiğini ifade etmektedir.

Çizelge 3. KYB karışım oranları $\left(\mathrm{kg} / \mathrm{m}^{3}\right)$

\begin{tabular}{|c|c|c|c|c|c|c|c|c|c|}
\hline \multirow{2}{*}{ Kod } & \multirow{2}{*}{ Su/Bağlayıc1 } & \multicolumn{2}{|c|}{ Toplam Bağlayıc Miktarı } & \multirow{2}{*}{$\begin{array}{c}\text { Toplam } \\
\text { Agrega }\end{array}$} & \multirow{2}{*}{ İi Agrega } & \multicolumn{2}{|c|}{ İnce Agrega } & \multirow{2}{*}{ SA* } \\
\cline { 5 - 6 } & & Çimento & UK & ACT & & DK* & KK* & \\
\hline KYBK & 0,32 & 440 & 110,0 & 0,0 & 620,4 & 822,0 & 579,8 & 244,7 & 7,60 \\
\hline KYBC5 & 0,32 & 440 & 82,5 & 27,5 & 623,3 & 825,9 & 582,5 & 245,9 & 8,18 \\
\hline KYBC10 & 0,32 & 440 & 55,0 & 55,0 & 626,2 & 829,7 & 585,2 & 247,0 & 9,65 \\
\hline KYBC15 & 0,32 & 440 & 27,5 & 82,5 & 629,1 & 833,6 & 587,9 & 248,2 & 10,52 \\
\hline KYBC20 & 0,32 & 440 & 0,0 & 110,0 & 632,0 & 837,4 & 590,6 & 249,3 & 11,40 \\
\hline
\end{tabular}

*SA: Süper Akışkanlaştırıcı, D.K: Doğal Kum, K.K: Kırma Kum 


\subsection{Deney Yöntemleri}

\subsubsection{Taze Beton Deneyleri}

Üretilen KYB'ler üzerinde, slump yayılma çapı ve $\mathrm{T}_{500(\mathrm{~mm})}$ slump yayilma süresi deneyi, V hunisi boşalma süresi deneyi ve L kutusu yükseklik oranı deneyi yapılmıştır. Yapılan deneyler Şekil 4'de sırasıyla gösterilmiştir.

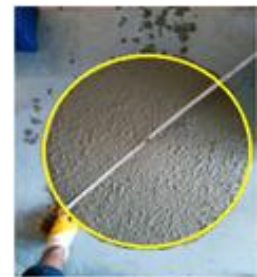

(a)

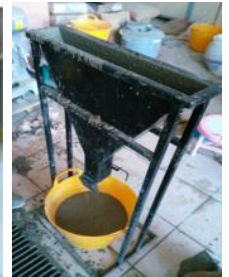

(b)

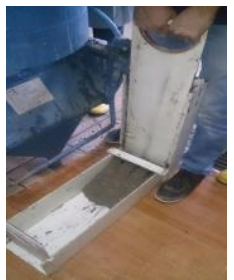

(c)
Şekil 4. a) Slump yayılma çap1, b) V hunisi boşalma süresi ve c) L kutusu yükseklik oranı deneyleri

Slump yayılma, $\mathrm{T}_{500(\mathrm{~mm})}$ slump yayılma süresi, V hunisi boşalma süresi ve L kutusu yükseklik oranı deneyleri EFNARC [21] standardına uygun olarak yapılmıştır. Slump yayılma deneyi taze halde bulunan betonun akış yeteneğini belirlemek için yapılmakta olup, oluşturulan karışımlar yayılma tablasının üzerinde bulunan Abrams konisinin içine sıkıştırma işlemine tabi tutulmaksızın yerleştirilmiştir. Koninin kaldırılmasıyla taze betonun $500 \mathrm{~mm}$ çapında tablada belirli olan çembere ilk ulaşma süresi $\mathrm{T}_{500(\mathrm{~mm})}$ slump yayılma süresi olarak belirlenmiştir. Yayılma çapı birbirine dik iki doğrultuda ölçülerek ve ortalamaları alınarak bulunmuştur. KYB karışımlarından ölçülen yayılma çapları Çizelge 4'de verilen EFNARC [21] sınır değerleri ile, $\mathrm{T}_{500(\mathrm{~mm})}$ slump yayılma süresi ise Çizelge 5'de verilen EFNARC [21] sınır değerleri ile kıyaslanmıştır.

Çizelge 4. EFNARC'a [21] göre slump yayılma çapı sınır değerleri

\begin{tabular}{|c|c|}
\hline $\begin{array}{c}\text { Slump Yayılma } \\
\text { Sinıflar1 }\end{array}$ & $\begin{array}{c}\text { Slump Yayılma } \\
\text { Çaplar1 }\end{array}$ \\
\hline SF1 & $550-650$ \\
\hline SF2 & $660-750$ \\
\hline SF3 & $760-850$ \\
\hline
\end{tabular}

V hunisinin boşalma süresi KYB karışımının viskozitesi hakkında bilgi vermekte olup, bu deneyde, KYB karışımları, Şekil 4(b)'de verilen V hunisine sıkıştırılmaksızın doldurulmuş ve doldurma işlemi tamamlandığında huninin üst yüzeyi mala yardımıyla düzeltilmiştir. Bu adımdan sonra, huninin altında bulunan kapağın açılmasıyla KYB'nin huniden boşalma süresi tespit edilerek karışımın viskozitesi hakkında bilgi edinilmiştir. V hunisi deney sonuçları Çizelge 5'de sunulan sınır değerler ile kıyaslanarak yorumlanmıştır.

L kutusu yükseklik oranı deneyi ise oluşturulan KYB karışımlarının sık donatılı alanlar veya dar açıklık gibi yerlere segregasyona ve bloklaşmaya sebep olmayacak şekilde homojen olarak yerleşip yerleşemediğini göstermektedir. Dolayısıyla bu deney yardımıyla KYB'nin geçiş yeteneği ölçülmektedir. Üretilen KYB'lerin karıştırma işlemi tamamlandığında, hiçbir şekilde bekletme olmaksızın, L kutusunun kapalı bölümüne doldurulmuştur. Doldurma esnasında herhangi bir vibrasyon işlemi uygulanmamıştır. Doldurmanın hemen ardından kapak sabit bir hızla yukarı doğru çekilmiş ve betonun demir çubuklar arasından geçiş yeteneği iki uç noktadaki kotun birbirine oranı $\left(\mathrm{h}_{2} / \mathrm{h}_{1}\right)$ ile tespit edilmiştir. Deney sonuçları Çizelge 5'de verilen sınır değerler ile kıyaslanmıştır.

Çizelge 5. EFNARC'a [21] göre viskozite ve geçebilme kabiliyeti sınıfları

\begin{tabular}{|c|c|c|c|c|}
\hline \multicolumn{2}{|c|}{ Sinıflar } & $\begin{array}{l}\text { T500 mm } \\
\text { Slump } \\
\text { Yayilma } \\
\text { Süresi (sn) }\end{array}$ & $\begin{array}{c}\text { V-Hunisi } \\
\text { Boşalma } \\
\text { Süresi } \\
\text { (sn) }\end{array}$ & $\begin{array}{c}\text { L Kutusu } \\
\text { Yükseklik } \\
\text { Oranı } \\
\left(\mathrm{h}_{2} / \mathrm{h}_{1}\right)\end{array}$ \\
\hline \multirow{2}{*}{ 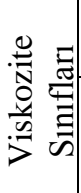 } & $\begin{array}{l}\text { VS1/ } \\
\text { VF1 }\end{array}$ & $\leq 2$ & $\leq 8$ & \\
\hline & $\begin{array}{l}\mathrm{VS} 2 / \\
\mathrm{VF} 2\end{array}$ & $>2$ & $9-25$ & \\
\hline \multirow{2}{*}{ 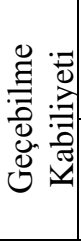 } & PA1 & & & $\begin{array}{c}\geq 0,8 \text { iki } \\
\text { çubuk } \\
\text { donatı }\end{array}$ \\
\hline & PA2 & & & $\begin{array}{c}\geq 0,8 \text { üç } \\
\text { çubuk } \\
\text { donatı }\end{array}$ \\
\hline
\end{tabular}




\subsubsection{Sertleşmiş Beton Deneyleri}

\subsubsection{Mekanik Deneyler}

KYB'nin mekanik özelliklerini tespit etmek amacıyla sertleşmiş numuneler üzerinde 28 . ve 56. günlerde, basınç, yarmada çekme ve eğilme dayanımı deneyleri yapılmıştır. Basınç, yarmada çekme ve eğilme dayanımı deneylerinde her karışım için sırasıyla, 6 adet $15 \times 15 \times 15$ cm'lik küp numuneler, 6 adet $10 \mathrm{~cm}$ çapında, $20 \mathrm{~cm}$ yüksekliğinde silindir numuneler ve 6 adet 10x10x40 cm'lik kiriş numuneler $23 \pm 2{ }^{\circ} \mathrm{C}$ 'de kür havuzunda bekletildikten sonra deneye tabi tutulmuştur. $\mathrm{Bu}$ deneyler için belirtilen numunelerin yarısı 28. günde, diğer yarısı ise 56. günde kullanılmıştır. Elde edilen sonuçlar her iki test yaşı için de ortalama alınarak belirlenmiştir. Basınç, yarmada çekme ve eğilme dayanımı deneyleri sirasiyla, ASTM C39 [22], ASTM C496 [23] ve ASTM C293/C293M-10 [24] standartlarına uygun olarak yapılmış olup deneylere ait görseller sirasıyla Şekil 5'de gösterilmiştir.

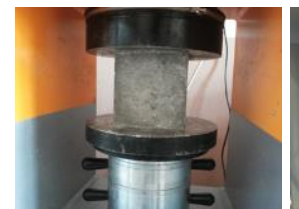

(a)

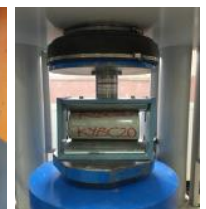

(b)

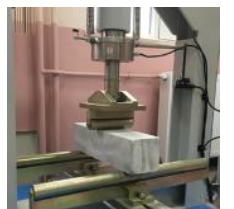

(c)
Şekil 5. a) Basınç dayanımı deneyi b) Yarmada çekme dayanımı deneyi ve c) Eğilme dayanımı deneyi

\subsubsection{Durabilite Deneyleri}

Kılcal su geçirimliliği deneyi, $100 \mathrm{~mm}$ çapında ve $200 \mathrm{~mm}$ uzunluğunda üretilen silindir numunelerden kesilen, $100 \mathrm{~mm}$ çapında ve $50 \mathrm{~mm}$ uzunluğundaki 3 'er adet numune üzerinde 28 . ve 56. günde uygulanmıştır. Deneyden önce numuneler 24 saat boyunca (numunelerin sabit kütleye ulaşması için geçmesi gereken süre) etüv içerisinde $100 \pm 5^{\circ} \mathrm{C}$ 'de kurutulmuştur. Daha sonra numunelerin su emmeye birakılacak yüzeylerinin yan tarafları su geçirimliliğini engellemek için yaklaşık $1 \mathrm{~cm}$ derinliğinde, silikon kullanılarak kaplanmıştır. Daha sonra numunelerin kuru ağırlığı tartılmış ve Şekil 6(a)'da görüldüğü üzere cam fanus içerisine yerleştirilmiştir. Cam fanus içerisindeki su yüksekliği, bilyelerin $0,5 \mathrm{~cm}$ üzerinde olacak şekilde ayarlanmıştır. Ardından 1., 4., 9., 16., 25., 36., 49. ve 64. dakikalarda numunelerin ağırlıkları, su emen yüzeyleri nemli bir bezle silindikten sonra tartılmıştır. Bu işlemlerden sonra numunelerin kılcal su geçirimliliği değerleri hesaplanmış olup, her karışım için 3 numunenin ortalaması alınmıştır.

Betona iletilen elektrik akımının Coulombs (C) cinsinden hesaplanması esasına dayanan hızlı klor geçirimliliği deneyi, ASTM C 1202 [25] standartlarına uygun olarak yapılmıştır. Deney, $100 \mathrm{~mm}$ çapında ve $200 \mathrm{~mm}$ uzunluğunda üretilen silindir numunelerden kesilen, $100 \mathrm{~mm}$ çapında ve $50 \mathrm{~mm}$ uzunluğundaki 3 'er adet numune üzerinde 28. ve 56. günde uygulanmıştır. Numuneler vakum makinasında 2 saat bekletilerek içindeki havanın alınmasıyla suya doygun hale getirilmiştir. Vakum makinasından çıkarılan numunelerin etrafı yalıtkan bir malzeme ile kaplandıktan sonra Şekil 6(b)'de görülen deney hücresinin ortasına yerleştirilmiştir. Hücrenin bir tarafı $0,3 \mathrm{NaOH}$ diğer tarafi ise $\% 3$ $\mathrm{NaCl}$ çözeltisi ile doldurularak $60 \mathrm{~V}$ sabit potansiyel fark altında 6 saat sonunda numunelerden geçen elektrik akımının şiddeti ölçülmüştür.

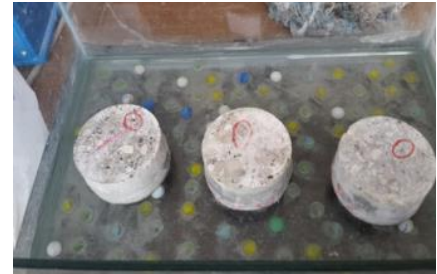

(a)

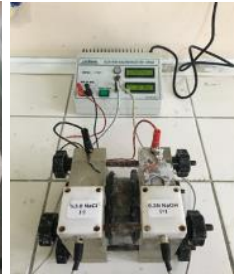

(b)
Şekil 6. a) Kılcal su geçirimliliği deneyi ve b) Hızlı klor geçirimliliği deneyi

\section{BULGULAR VE TARTIŞMA}

\subsection{Slump Yayılma Çapı, $\mathbf{T}_{\mathbf{5 0 0}(\mathrm{mm})}$ Slump Yayılma Süresi, V Hunisi Boşalma Süresi ve L Kutusu Yükseklik Oranı}

KYB karışımlarının süper akışkanlaştırıcı miktarı karışımların segregasyona uğramadan yayılmasını 
sağlayacak şekilde belirlenmiş olup, karıșımlar $700 \pm 10$ mm sabit bir yayılma çapıyla üretilmiştir. Karışımların slump yayılma çapı ve $T_{500(\mathrm{~mm})}$ slump yayılma süresi sırasıyla, Şekil 7 ve Şekil 8'de gösterilmiştir. Çizelge 3'den de görüldüğü gibi karışımlarda kullanılan ACT miktarı arttıkça, istenilen yayılma aralığını elde edebilmek için kullanılan SA miktarının arttığı görülmektedir. KYB karışımlarının slump yayılma çaplarının EFNARC [21] standartlarına uygun olduğu belirlenmiş olup, en düşük yayılma çapının KYBC20 için $690 \mathrm{~mm}$ ve en yüksek yayılma çapının ise KYBK için $710 \mathrm{~mm}$ olduğu belirlenmiştir. Çizelge 4'deki slump yayılma çaplarının sınır değerleri ile Şekil 7'de karışımlar için belirtilen slump yayılma çapları karşılaştırıldığında, üretilen bütün KYB karışımlarının SF2 sınıfında olduğu belirlenmiştir. En yüksek $\mathrm{T}_{500(\mathrm{~mm})}$ slump yayılma süresi KYBC20 karışımında 6,32 saniye olarak belirlenmiş olup kontrol karışımından 2,85 saniye daha geç yayılmıştır. Şekil 8'de verilen $\mathrm{T}_{500(\mathrm{~mm})}$ slump yayılma süreleri, Çizelge 5 'de verilen viskozite sınır değerlerine göre incelendiğinde, KYB karışımlarının VS2 viskozite sınıfı içerisinde yer aldığı belirlenmiştir.

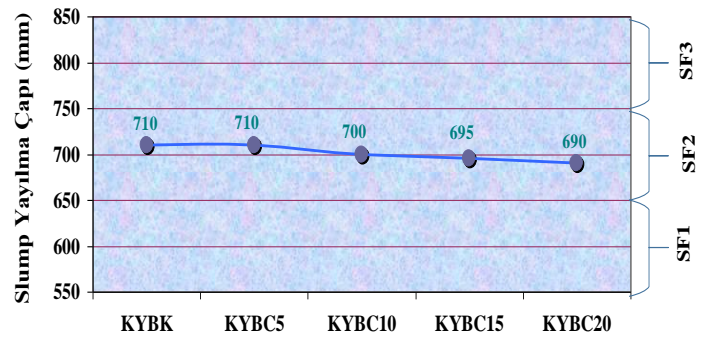

Şekil 7. KYB'lerin slump yayılma çapı değerleri

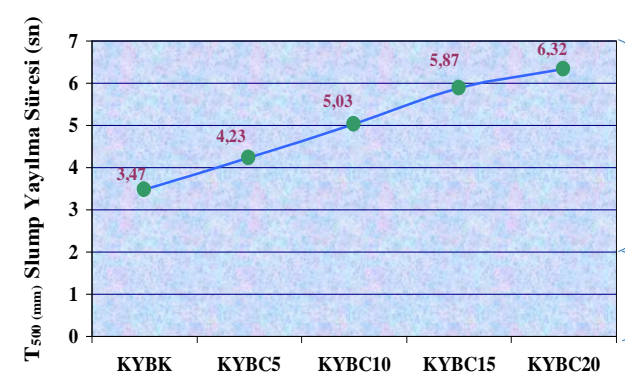

Şekil 8. KYB'lerin $\mathrm{T}_{500(\mathrm{~mm})}$ slump yayılma süresi değerleri
Şekil 9'da V hunisi boşalma süresi deney sonuçları verilmiş olup bu sonuçlara göre KYB karışımlarının içeriğindeki UK miktarının azalması ve ACT miktarının artması ile $\mathrm{V}$ hunisi boşalma süresinin arttığı belirlenmiştir. En düşük boşalma süresi 16,1 saniye ile KYBK karışımında elde edilmiştir. $\mathrm{Bu}$ karışıma göre $\mathrm{V}$ hunisi boşalma süresindeki en büyük artış KYBC20 karışımında belirlenmiş olup bu artış \%30,99 seviyesindedir. Çizelge 5'de belirtilen viskozite sınıflarına göre V hunisi boşalma süresi 9 sn ile 25 sn arasında olan karışımlar VF2 sınıfında yer almaktadırlar. Dolayısıyla, bu çalışmada üretilen bütün KYB karışımlarının VF2 viskozite sınıfında yer aldığı tespit edilmiştir.

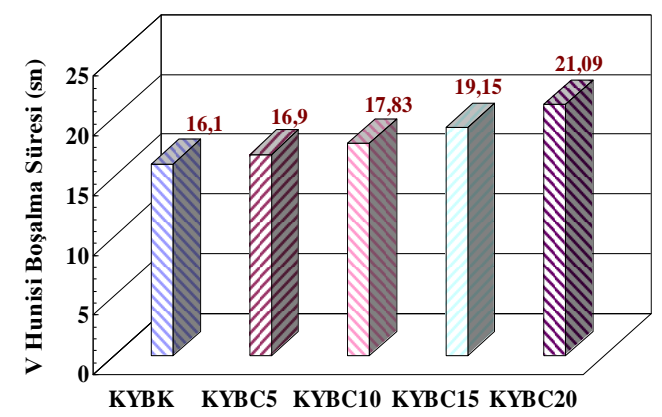

Şekil 9. KYB'lerin V hunisi boşalma süresi değerleri

KYB karışımlarının sık donatılı ve dar alanlardaki geçiş yeteneğini belirlemek amacıyla uygulanan L kutusu yükseklik oranı deneyinden elde edilen sonuçlar Şekil 10'da sunulmuştur. L kutusu yükseklik oranı deneyinden elde edilen sonuçlar incelendiğinde, karışımlardaki UK miktarının azalması ve ACT miktarının artmasıyla $\mathrm{h}_{2} / \mathrm{h}_{1}$ oranının düştüğü belirlenmiştir. KYBK karışımının $\mathrm{h}_{2} / \mathrm{h}_{1}$ oranı 0,88 ile en yüksek değeri aldığ KYBC20 karışımının ise $h_{2} / h_{1}$ oranı 0,82 ile en düşük değeri aldığı saptanmıştır. Dolayısıyla ACT'nin, UK mineraline göre KYB'lerin işlenebilirlik özelliğini azalttığı ortaya çıkmıştır. Bununla birlikte, Şekil 10'da görüldüğü gibi $\mathrm{h}_{2} / \mathrm{h}_{1}$ oranının üretilen bütün KYB karışımları için EFNARC'da [21] belirtilen 0,8'den büyük olma koşulunu sağladığg ve geçiş yeteneği sınıfının PA2 olduğu tespit edilmiştir. 


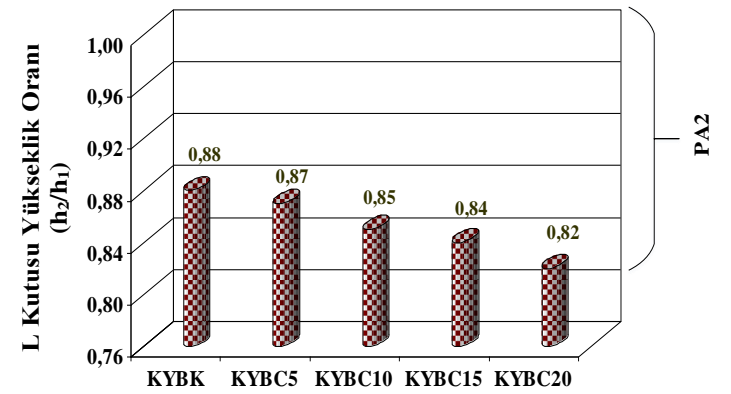

Şekil 10. KYB'lerin L kutusu yükseklik oranı değerleri

Üretilen KYB karışımlarının taze özellikleri incelendiğinde KYBK karışımının KYBC karışımlarına oranla işlenebilirliğinin daha yüksek olduğu belirlenmiştir. KYBC karışımlarına bakıldığında ise giderek artan ACT miktarının slump yayılma çapı ve L kutusu yükseklik oranında azalma, $\mathrm{T}_{500(\mathrm{~mm})}$ slump yayılma ve V hunisi boşalma sürelerinde ise artışa yol açtığg gözlemlenmiştir. Bu sonuçlara göre ACT ve UK atık katkı malzemeleri kıyaslandığında UK'nin, ACT'ye göre işlenebilirliği olumlu yönde etkileyen bir malzeme olduğu anlaşılmıştır. $\mathrm{Bu}$ durum iki temel nedenle açıklanabilir. Bunların birincisi, Şekil 2'de görüldüğü gibi ACT'nin UK'ye göre daha ince bir parçacık boyutuna sahip olmasıdır. Bu nedenle, ACT, UK'ye göre daha yüksek bir yüzey alanına sahiptir ve bu da daha fazla su ihtiyacı anlamına gelmektedir [26]. İkinci temel neden ise Şekil 3'de verilen SEM analizi ile açıklanabilir. $\mathrm{Bu}$ analize göre UK'nin mikro yapıdaki tanecik görüntüsü ACT'ye göre daha dairesel bir yapıya sahiptir. Bu durum UK mineralinin KYB karışımlarındaki akışkanlığı arttırıcı bir etkiye sahip olmasını sağlamaktadır [27].

\subsection{Basınç Dayanımı, Yarmada Çekme Dayanımı ve Eğilme Dayanımı}

KYB karışımlarının basınç dayanımı değerleri Şekil 11'de gösterilmiş olup, KYBK karışımının 28. ve 56. günlerdeki basınç dayanımları sırasıyla, $65,7 \mathrm{MPa}$ ve 73,1 $\mathrm{MPa}$ olarak tespit edilmiştir. 28 günlük basınç dayanımı test sonuçları dikkate alınarak KYBK karışımına göre, KYBC5,
KTBC10, KYBC15 ve KYBC20 karışımlarının basınç dayanımları artışı sırasıyla, \%4,25, \%8,98, $\% 13,87$ ve $\% 17,78$ olarak bulunmuştur. Aynı karışımların 56 günlük basınç dayanımı test sonuçları incelendiğinde, kontrol karışımına göre değer artışları sırasılyla, \%5,40, \%8,96, \%12,82 ve $\% 17,78$ olarak tespit edilmiştir. Dolayısıyla, UK yerine kullanılan ACT miktarının artması her iki test yaşı için de basınç dayanımını arttırmış olup, bu artış KYBC20 karışımında en yüksek değerine ulaşmıştır. Ayrıca 56 günlük basınç dayanımları 28 günlük basınç dayanımları ile karşılaştırıldığında, KYBK, KYBC5, KYBC10, KYBC15 ve KYBC20 karışımları için sırasıyla, \%11,26, \%12,50, $\% 11,24, \% 10,24$ ve $\% 11,27$ oranlarında dayanım artışı elde edilmiştir.

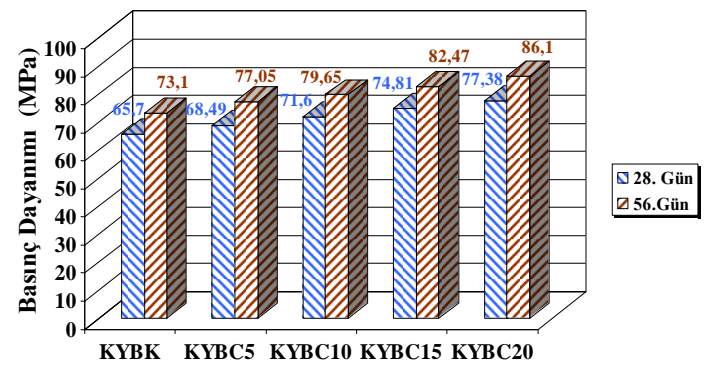

Şekil 11. KYB'lerin basınç dayanımı değerleri

KYB karışımlarının yarmada çekme dayanımı değerlerinin gösterildiği Şekil 12'deki 28 ve 56 günlük deney sonuçlarına göre, en düşük dayanım değerleri KYBK karışımında, en yüksek dayanım değerleri ise KYBC20 karışımında elde edilmiştir. KYBK karışımı için bu değerler, 28. ve 56. günlerde sirasıyla 5,08 $\mathrm{MPa}$ ve 5,46 $\mathrm{MPa}$ iken, KYBC20 karışımı için sırasıyla 5,99 $\mathrm{MPa}$ ve 6,41 $\mathrm{MPa}$ olarak tespit edilmiştir. $\mathrm{Bu}$ sonuçlara göre, UK yerine kullanılan ACT yüzdesi arttıkça KYB'nin yarmada çekme dayanımı değerleri artmıştır. Kür periyodunun yarmada çekme dayanımı artışına olan olumlu etkisini görebilmek amaciyla KYBK, KYBC5, KYBC10, KYBC15 ve KYBC20 karışımlarının 28. ve 56. günlerdeki dayanım değerleri karşılaştırılmıştır. 56. gündeki yarmada çekme dayanımı değerleri 28. güne göre sirasiyla, 1,07, 1,08, 1,07, 1,06 ve 1,07 kat artmıştır. 


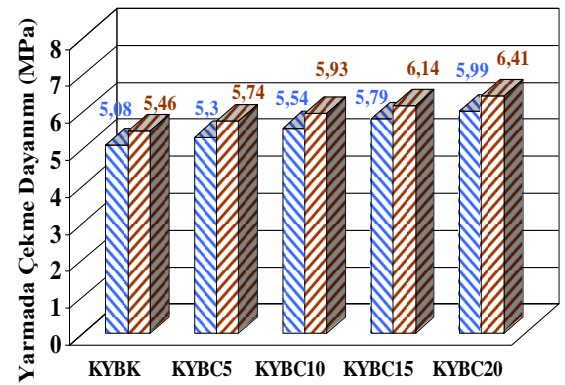

$\triangle 28$. Gün 七56. Gün

Şekil 12. KYB'lerin yarmada çekme dayanımı değerleri

Şekil 13'de verilen eğilme dayanımı deney sonuçları incelendiğinde, her iki test yaşı için en yüksek değerlerin KYBC20 karışımında elde edildiği saptanmıştır (28. gün için 7,99 MPa, 56. gün için 8,55 $\mathrm{MPa}$ ). Bu sonuçlara göre, KYBK karışımının eğilme dayanımı değerleri hem 28. hem de 56. günde KYBC karışımlarına göre daha düşüktür. Bununla birlikte, KYBC karışımlarının eğilme dayanımı değerleri ACT miktarının artmasıyla birlikte artmıştır. 28 günlük deney sonuçlarına bakıldığında, KYBC5, KYBC10, KYBC15 ve KYBC20 karışımlarının, KYBK'ye göre belirlenen eğilme dayanımı artışları sırasıyla, $\% 4,72, \% 8,90, \% 13,86$ ve $\% 17,85$ olarak belirlenmiştir. 56 günlük deney sonuçlarında ise bu artışlar sırasıyla, \%5,08, \%8,65, \%12,50 ve $\% 17,44$ 'tür. Sonuçlardan açıkça görüldüğü gibi KYB'de kullanılan ACT yüzdesinin artışı eğilme dayanımını artırmış ve \%20 ACT içeriğinde bu artış en yüksek değerine ulaşmıştır. Son olarak, 28. güne oranla, 56. gündeki dayanım artışları KYBK, KYBC5, KYBC10, KYBC15 ve KYBC20 için sirasılya, \%7,37, \%7,75, \%7,04, \%6,09 ve \%7,01 olarak tespit edilmiştir.

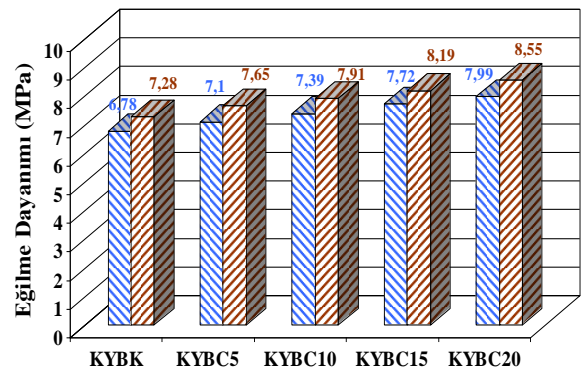

Q 28. Gün ๑56. Gün

Şekil 13. KYB'lerin eğilme dayanımı değerleri
Basınç dayanımı, yarmada çekme dayanımı ve eğilme dayanımı deney sonuçlarına göre UK mineralinin yerine kullanılan ACT miktarının artmasıyla, her iki test yaşı için KYB'nin mekanik özellikleri iyileşmiş olup, bu iyileşme \%20 ACT içeriğinde en yüksek değerine ulaşmıştır. ACT'nin bu geliştirici etkisinin temel nedeni, ACT'nin silis içeriğinin (\%73,90), UK mineralinin silis içeriğinden $(\% 57,20)$ daha fazla olmasıdır. Bilindiği gibi, puzolanik özellik gösteren mineral katkılar çimento yerine uygun oranlarda kullanıldığında, çimento ile suyun hidratasyonu sonucunda oluşan $\mathrm{Ca}(\mathrm{OH})_{2}$ 'i içeriğinde bulunan aktif $\mathrm{SiO}_{2}$ ile bağlayarak, betona ek dayanım kazandıran C-S-H (kalsiyum-silika-hidrat) jellerini oluşturmaktadır [15]. Buna ek olarak, Şekil 1'de verilen tane boyutu dağılımına göre, ACT, UK mineraline göre daha ince bir parçacık boyutuna sahiptir. Bu incelik sayesinde çimento matrisinde bulunan mikron boyutundaki gözeneklerde doldurucu bir etki sağlanmış ve böylece daha kompakt bir yapı oluşması sağlanmıştır [14]. Tane boyutu dağılımına paralel olarak ACT ve UK minerallerinin özgül yüzey alanları sırasıyla $492 \mathrm{~m}^{2} / \mathrm{kg}$ ve $379 \mathrm{~m}^{2} / \mathrm{kg}$ olarak ölçülmüştür. Bilindiği gibi daha yüksek özgül yüzey alanı puzolanın hidratasyondaki oranını arttırır [28]. Tüm bunlara ek olarak, basınç dayanımı, yarmada çekme dayanımı ve eğilme dayanımı için 28. güne oranla, 56. günde meydana gelen artış ise devam eden hidratasyon süreci ile açıklanabilir [18].

\subsection{Kılcal Su Geçirimliliği ve Hızlı Klor Geçirimliliği}

KYB karışımlarının kılcal su geçirimliliği değişimleri Şekil 14'de verilmiştir. Deney sonuçlarına göre, KYBK karışımının kılcal su geçirimliliği değerleri, 28 . günde $0,0755 \mathrm{~cm} / \mathrm{s}$ ve 56 . günde $0,0637 \mathrm{~cm} / \mathrm{s}$ olarak belirlenmiş olup, bu değerler tüm karışımlar arasındaki en yüksek değerlerdir. KYBC20 karıșımı ise 28. günde $0,0651 \mathrm{~cm} / \mathrm{s}$ ve 56 . günde $0,0528 \mathrm{~cm} / \mathrm{s}$ değerleri ile tüm karışımlar arasında en düşük değerlere sahip olan karışım olmuştur. Değerlerde gözlemlenen bu azalma, ACT yüzdesinin artmasına bağlı olarak devam etmiştir. Şekil 14'e göre kür etkisi 
Uçucu Kül Yerine Kullanılan Atık Cam Tozunun Kendiliğinden Yerleşen Betonların Taze, Mekanik ve Durabilite Özellikleri Üzerine Etkisi

incelendiğinde, KYB’lerin 56. gündeki k1lcal su geçirimliliği değerlerinin 28. güne göre daha düşük olduğu belirlenmiştir. Dolayısıyla, kür etkisi arttıkça KYB'lerin kılcal su geçirimliliği azalmıştır.

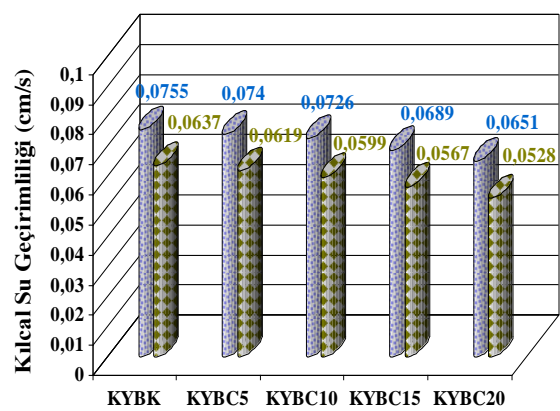

28. Gün ๑56. Gün

Şekil 14. KYB'lerin kılcal su geçirimliliği değerleri

Hızlı klor geçirimliliği deneyinden elde edilen Coulombs (C) değerleri Şekil 15'de gösterilmiştir. Deney sonuçlarına göre, KYBK karışımının 28. ve 56. gündeki $\mathrm{C}$ değerleri sirasıyla, 2732 ve 1524 iken, KYBC20 karışımının aynı günlerdeki C değerleri ise sırasıyla, 2208 ve 1066 olarak tespit edilmiştir. Şekil 15'de gösterildiği gibi ACT mineralinin kullanım miktarı arttıkça KYB'lerin klor iyonu geçirimliliği azalmaktadır. Buna ek olarak, ASTM C 1202 [25] standardındaki sınır değerlere göre $\mathrm{C}$ değeri, $0-1000 \mathrm{C}$ aralığında ise iyon geçirimliliği çok düşük, 1000-2000 C aralığında ise iyon geçirimliliği düşük, 2000-4000 C aralığında ise iyon geçirimliliği orta ve 4000 C'den daha büyük ise iyon geçirimliliği yüksektir. Dolayısıyla, bütün KYB'ler 28. gün için orta derecede klor iyonu geçirimliliğine, 56. gün için ise düşük klor iyonu geçirimliliğine sahiptir. $\mathrm{Bu}$ nedenle, bu çalışmada üretilen bütün KYB'ler inşaat sektöründe çeşitli klor atağ yapılar için önleyici olarak kullanılabilir. Bunun dışında, 28. güne göre 56. gündeki değişimler dikkate alındığında kür etkisinin geçirimsizlik özelliğine olan olumlu etkisi görülmektedir. KYBK, KYBC5, KYBC10, KYBC15 ve KYBC20 karışımları için 28. güne göre 56. günde meydana gelen değer artışları sırasıyla, \%44,21, \%46,98, $\% 49,96, \% 53,38$ ve $\% 51,72$ olarak belirlenmiştir.

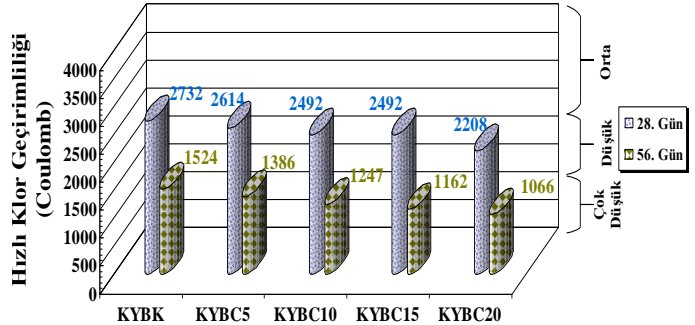

Şekil 15. KYB'lerin hızlı klor geçirimliliği değerleri

Kılcal su geçirimliliği ve hızlı klor geçirimliliği deney sonuçlarına göre UK yerine kullanılan ACT miktarı arttıkça KYB'nin durabilite performansının geliştiği belirlenmiştir. ACT'nin UK'ye göre daha yüksek özgül yüzey alanına ve daha ince tane boyutuna sahip olduğu sırasıyla, Çizelge 1 ve Şekil 1 'de görülmektedir. Bu durum KYB'de kullanılan ACT miktarının artmasıyla birlikte çimento matrisindeki mikro ölçekli gözenek yapılarının, ACT'nin doldurucu etkisi sayesinde azalmasını sağlamıştır. Böylece daha yoğun ve daha kompakt bir matris yapısı oluşmakta, bu sayede çimento matrisinin geçirimsizliği artmaktadır [29]. Ayrıca, kılcal su geçirimliliği ve hızlı klor geçirimliliği için 28. güne oranla, 56. günde geçirimsizlikte meydana gelen gelişim ise devam eden hidratasyon periyodu ile açıklanabilir [29].

\section{SONUÇLAR}

$\mathrm{Bu}$ çalışmada ACT, UK yerine belirli oranlarda kullanılarak KYB'ler üretilmiş olup, KYB'lerin taze ve sertleşmiş haldeki özellikleri belirlenmiştir. Böylece ACT ile UK minerallerinin taze, mekanik ve durabilite özellikleri üzerine etkisi incelenmiş ve elde edilen sonuçlar aşağıda verilmiştir.

- KYB karışımları incelendiğinde, kullanılan ACT miktarı arttıkça, KYB'lerin slump yayılma çapı ve L kutusu yükseklik oranı değerleri azalmıştır. Buna paralel olarak, $\mathrm{T}_{500(\mathrm{~mm})}$ slump yayılma süresi ve $\mathrm{V}$ hunisi boşalma süresi değerleri ACT kullanım yüzdesi arttıkça artmıştır. Bu sonuçlara göre, ACT minerali, KYB'nin işlenebilirliğini azaltmıştır. $\mathrm{Bu}$ durum minerallerin SEM görüntüleriyle 
desteklenebilir. SEM sonuçlarına göre, UK, ACT'ye göre daha dairesel bir parçacık yapısına sahiptir. Bu nedenle UK ile KYB'ler daha akıcı bir özellik göstermektedir.

- KYB içeriğindeki ACT artışına bağlı olarak KYB'lerin basınç dayanımı, yarmada çekme dayanımı ve eğilme dayanımı değerleri her iki test yaşı (28 ve 56) için yükselmiştir. Bu durum puzolanik özellik gösteren ACT ve UK minerallerinin silis içeriğiyle, tane boyutu dağılımlarıyla ve özgül yüzey alanlarıyla açıklanabilir. ACT'nin silis içeriğinin ve özgül yüzey alanının UK ile karşılaştırıldığında daha yüksek olduğu belirlenmiştir. Ayrıca, ACT, UK'ye göre daha ince tane boyutu dağılıma sahiptir. $\mathrm{Bu}$ nedenlerden dolayı, ACT kullanımı arttıkça ek C-S-H jelleri ile beraber dayanım artışı sağlanmış, yüksek özgül yüzey alanı ve daha ince tane boyutu dağılımı ise bu artışı olumlu yönde etkilemiştir.

- KYB’nin ACT artışı sonucu gelişen durabilite performansı bu mineralin UK'ye göre sahip olduğu daha ince tane boyutu dağılımı ve daha yüksek özgül yüzey alanı ile açıklanabilir. $\mathrm{Bu}$ özellikler ile daha yoğun ve daha kompakt bir matris yapısı oluşmakta, böylece çimento matrisinin geçirimliliği azalmaktadır.

- Son olarak kür süresinin KYB'ye olan olumlu etkisi, hem mekanik hem de durabilite deneyleriyle belirlenmiştir. $\mathrm{Bu}$ deney sonuçlarına göre, KYB'lerin 56. gündeki performansları 28. güne göre daha yüksektir. $\mathrm{Bu}$ durum bağlayıcı malzemeler ile suyun devam eden hidratasyon periyoduna bağl1 olarak açıklanabilir.

\section{KAYNAKLAR}

1. Omrane, M., Kenai, S., Kadri, E.H., Ait Mokhtar, A., 2017. Performance and Durability of Self Compacting Concrete using Recycled Concrete Aggregates and Natural Pozzolan, Journal of Cleaner Production, 165, 415-430.

2. Felekoğlu, B., Türkel, S., Baradan, B., 2004. Kendiliğinden Yerleşen Beton Potansiyel
Avantaj ve Dezavantajları, İMO İzmir Şubesi, 120.

3. Felekoglu, B., 2003. Kendiliğinden Yerleşen Betonun Fiziksel ve Mekanik Özelliklerinin Araştırılması, Yüksek Lisans Tezi, Dokuz Eylül Üniversitesi, Fen Bilimleri Enstitüsü, İzmir.

4. Khatib, J.M., 2008. Performance of Self Compacting Concrete Containing Fly Ash, Construction and Building Materials, 22, 1963-1971.

5. Lena, E.D., Spinelli, M., Martínez, I., Gatti, M., Scaccabarozzi, R., Cinti, G., Romano, M.C., 2017. Process Integration Study of TailEnd Ca-Looping Process for $\mathrm{CO}_{2}$ Capture in Cement Plants, International Journal of Greenhouse Gas Control, 67, 71-92.

6. Gutiérrez, A.S., Eras, J.J.C., Gaviria, C.A., Caneghem, J.V., Vandecasteele, C., 2017. Improved Selection of The Functional Unit in Environmental Impact Assessment of Cement, Journal of Cleaner Production, 168, 463-473.

7. Chen, C., Habert, G., Bouzidi, Y., Jullien, A., 2010. Environmental Impact of Cement Production: Detail of the Different Processes and Cement Plant Variability Evaluation, Journal of Cleaner Production, 18, 478-485.

8. Abbasa, S., Saleema, M.A., Kazmib, S.M.S., Munir, M.J., 2017. Production of Sustainable Clay Bricks Using Waste Fly Ash: Mechanical and Durability Properties, Journal of Building Engineering, 14, 7-14

9. Oner, A., Akyuz, S., Yildiz, R., 2005. An Experimental Study on Strength Development of Concrete Containing Fly Ash and Optimum Usage of Fly Ash in Concret, Cement and Concrete Research, 35(6), 1165-1171.

10. Munir, M.J., Qazi, A.U., Kazmi, S.M.S., Khitab, A., Ashiq, S.Z., Ahmed I., 2016. A Literature Review on Alkali Silica Reactivity of Concrete in Pakistan, Pakistan Journal of Science, 68(1), 53-62.

11. Nagaratnam, B.H., Rahman, M.E., Mirasa, A.K., Mannan, M.A., Lame, S.O., 2016. Workability and Heat of Hydration of SelfCompacting Concrete Incorporating AgroIndustrial Waste, Journal of Cleaner Production, 112, 882-894. 
12. Kim, J.K., Han, S.H., Park, Y.D., Noh, J.H., Park, C.L., Kwon, Y.H., Lee, S.G., 1996. Experimental Research on the Material Properties of Super Flowing Concrete, in: Bartos, P.J.M., Marrs, D.L., Cleland, D.J., (Eds.), Production Methods and Workability of Concrete, E\&FN Spon, 271-284.

13. Mahalingam, B., Nagamani, K., Kannan, L.S., Haneefa, K.M., Bahurudeen, A., 2016. Assessment of Hardened Characteristics of Raw Fly Ash Blended Self-Compacting Concrete, Perspectives in Science, 8, 709-711.

14. Vijayakumar, G., Vishaliny, H., Govindarajulu, D., 2013. Studies on Glass Powder as Partial Replacement of Cement in Concrete Production, International Journal of Emerging Technology and Advanced Engineering, 3(2), 153-157.

15. Lee, H., Hanif, A., Usman, M., Sim, J., Oh, H., 2018. Performance Evaluation of Concrete Incorporating Glass Powder and Glass Sludge Wastes as Supplementary Cementing Material Journal of Cleaner Production, 170, 683-693.

16. Khmiri, A., Chaabouni, M., Samet, B., 2013. Chemical Behaviour of Ground Waste Glass When used as Partial Cement Replacement in Mortars, Construction and Building Materials, 44, 74-80.

17. Vanjare, M.B., Mahure, S.H., 2012. Experimental Investigation on Self Compacting Concrete using Glass Powder, International Journal of Engineering Research and Applications, 2(3), 1488-1492.

18. Du, H., Tan, K.H., 2017. Properties of High Volume Glass Powder Concrete, Cement and Concrete Composites, 75, 22-29.

19. Aliabdo, A.A., Abd Elmoaty M., Abd Elmoaty, Ahmet, Y. Aboshama, 2016. Utilization of Waste Glass Powder in the Production of Cement and Concrete, Construction and Building Materials, 124, 866-877.

20. ASTM C192/C192M, 2007. Standard Practice for Making and Curing Concrete Test Specimens in the Laboratory, ASTM International, West Conshohocken, PA, USA.

21. EFNARC, 2002. Specifications and Guidelines for Self-Compacting Concrete, EFNARC, Association House, 99 West Street, Farnham,
United Kingdom, www.efnarc.org, ISBN 0 953973344, 32.

22. ASTM C39, 2012. Standard Test Method for Compressive Strength of Cylindrical Concrete Specimens, ASTM International, West Conshohocken, PA, USA.

23. ASTM C496, 2011. Standard Test Method for Splitting Tensile Strength of Cylindrical Concrete Specimens, ASTM International, West Conshohocken, PA, USA.

24. ASTM C293/C293M-10, 2010. Standard Test Method for Flexural Strength of Concrete, ASTM International, West Conshohocken, PA, USA.

25. ASTM C1202, 2012. Standard Test Method for Electrical Indication of Concrete's Ability to Resist Chloride Ion Penetration, ASTM International, West Conshohocken, PA, USA.

26. Vandhiyan, R., Ramkuma, K., Ramya, R., 2013. Experimental Study on Replacement of Cement By Glass Powder, International Journal of Engineering Research \& Technology (IJERT), 2(5), 234-238.

27. Öz, H.Ö., Yücel, H.E., Güneş, M., 2017. Comparison of Glass Powder and Fly Ash Effect on the Fresh Properties of SelfCompacting Mortars, IOP Conference Series: Materials Science and Engineering, 245, 032036.

28. Yücel, H. E., Şahmaran, M., Yıldırım, G., Lachemi, M., 2014. Engineered Cementitious Composites As Sustainable Overlay Materials for Bridge Deck Applications, İstanbul Bridge Conference, İstanbul, August 11-13.

29. Liu, M., 2011. Incorporating Ground Glass in Self-Compacting Concrete, Construction and Building Materials, 25, 919-925. 